\title{
DINÂMICA DE MARÉ E TRANSPORTE DE SEDIMENTOS NO CANAL DE ITAJURU - LAGUNA DE ARARUAMA (RJ)
}

\author{
GUILHERME C. LESSA*
}

\begin{abstract}
TIDAL DYNAMICS AND SEDIMENT TRANSPORT AT ITAJURU CHANNEL - ARARUAMA LAGOON (RJ). The Itajuru channel, located in the Eastern side of the Araruama lagoon (Rio de Janeiro State), is RUAMA LAGOON (RJ). The Itajuru channel, located in the Eastern side of the Araruama lagoon (Rio de Janeiro State), is
probably the unique inverse estuarine system along the Southeast and South Brazilian coast The position of the sedimentary deposits, the hypersaline characteristics of the lagoon and its small catchment area, induced the idea that the flood currents might have more transport capacity than ebb currents. Field works carried out in summer 1988 and winter 1989 indicated the propagation of an asymmetrical tide, associated, however, with stronger flux of water ami sediment during ebb tide. The results seems to be related with a period of more humid climate, when the normal negative hydrological balance turns to be positive. The consequence has been an increase of the lagoon level and a set up of a pressure gradient towards the sea, with the predominance of the ebb currents.
\end{abstract}

Keywords: Estuary, tidal inlet, tide, sediment transport, tidal current, tidal asymmetry.

\begin{abstract}
RESUMO O Canal de Itajuru, localizado no extremo leste da laguna de Araruama (Estado do Rio de Janeiro), constitui talvez o único sistema estuarino inverso na costa sul e sudeste brasileira. A localização dos depósitos sedimentares no canal, aliada à hipersalinidade das águas da laguna e à reduzida área da bacia de drenagem, sugerem a existência de uma assimetria da onda de maré e fluxo de enchente com maior capacidade de transporte que o fluxo de vazante, proporcionando o entulhamento do canal com areias marinhas. Campanhas de medições realizadas no verão de 1988 e inverno de 1989 diagnosticaram a propagação de uma maré assimétrica associada, entretanto, a uma situação inversa, com fluxo de água e sedimentos na vazante superando o de enchente. Os resultados encontrados parecem relacionar-se a um período de maior umidade climática, quando o balanço preciphação-evaporação, normalmente negativo, passa a ser positivo. Este fato provoca maior armazenamento de água na laguna, acarretando aumento de nível desta e conseqüente aumento do gradiente de pressão direcionado para o mar, proporcionando o predomínio das correntes de vazantes.
\end{abstract}

Palavras-chaves: Estuário, canal da maré, transporte de sedimentos, correntes de maré, maré, assimetria de maré.

INTRODUÇ̃̃O A dinâmica de circulação de água e sedimentos em estuários não tem sido objeto freqüente de pesquisas geológicas no Brasil. Os trabalhos publicados geralmente traçam um paralelo entre a penetração de água marinha, o modelo de estratificação do fluxo e o deslocamento da zona de turbidez máxima (Dobereiner 1983, Ayup 1986, Moraes et al 1988), ou então da transição sazonal das fácies sedimentares nos estuários associadas às vazões fluviais, sem entretanto ser quantificado o volume de sólidos em trânsito (Dobereiner 1986, Ponçano \& Gimenez 1987). Sarros (1984) apresenta talvez o único trabalho sobre transporte de sedimentos em um estuário brasileiro, abordando a dinâmica das correntes de maré e o volume de sólidos transportados no estuário do Rio Potengi (RN). O autor acima observou que naquele estuário, localizado em região semi-úmida, as correntes são estabelecidas de acordo com a variação astronômica da maré. Esta penetra no estuário adquirindo assimetria negativa, produzindo correntes de vazante mais fortes do que as de enchente e a tendência de descarga dos sólidos transportados. Neste trabalho, será enfocada a penetração da maré e o transporte de sedimentos no canal de maré da laguna de Araruama.

A laguna de Araruama esta localizada no litoral sul do Estado do Rio de Janeiro, constituindo o último corpo lagunar (a leste) do sistema de lagunas associado à linha de cordões arenosos, que se extende da Restinga de Marambaia ao Cabo Frio (Fig. 1). É uma laguna hipersalina (salinidade média de $60 \%$, segundo Accetta 1986), com área de $200 \mathrm{~km}^{2}$, profundidade média de $3 \mathrm{~m}$ e volume correspondente a $6,4 \mathrm{x}$ $10^{18} \mathrm{~m}^{3}$. Seu contato com o mar ocorre através do Canal de Itajuru, posicionado no extremo leste da laguna (Fig. 2). O canal possui uma extensão de $83 \mathrm{~km}$, quase toda ela retificada, com largura e profundidade média de respectivamente $180 \mathrm{~m}$ e 1,6 m, sendo que esta última se reduz em direção à laguna. A embocadura, com $80 \mathrm{~m}$ de largura, é estável, estando localizada entre duas formações rochosas e em uma posição pouco sujeita ao ataque frontal das ondas, o que dificulta a deposição de sedimentos por efeito de correntes longitudinais e transversais.

A área ao norte da laguna é composta por um relevo de colinas rebaixadas, relacionadas a rochas pré-cambrianas (Fonseca et al 1987) e depósitos terciários.

A área sul é formada por uma planície de cordões arenosos, os quais dão origem às restingas de Massambaba e Cabo Frio. Com uma bacia de drenagem reduzida $\left(291 \mathrm{~km}^{2}\right)$ que se afunila para leste, a laguna possui apenas dois rios perenes que desaguam na sua porção oriental, sendo eles o Rio das Moças e o Rio Mataruna (Fig. 2).

O clima é tropical, mas relativamente seco. Um forte gradiente climático é indicado por Barbiére (1984), que classifica o clima de Iguaba Grande, de acordo com Köppen, como tropical (Aw"), e o de Arraial do Cabo como semi-árido (Bsh) - o período úmido para as duas localidades coincide com primavera e outono, e o período seco com verão e inverno. Os resultados do balanço precipitação-evaporação para os últimos 20 anos expressa bem o caráter mais árido da região em estudo (Fig. 3).

O litoral de Cabo Frio se caracteriza por um regime de micromaré mista, semi-diuma, com altura média de $1,1 \mathrm{~m}$ e número de forma, $\mathrm{K}=(\mathrm{K} 1+\mathrm{O} 1 / \mathrm{M} 2+\mathrm{S} 2)$, igual a 0,3 (Pond \& Pickard 1983). Ao entrar no canal, a maré sofre um amortecimento e atraso progressivo, deixando de ser percebida na altura de São Pedro D' Aldeia, a $14 \mathrm{~km}$ da embocadura (Accetta 1986, Fig. 2). Na laguna, o nível d'agua 


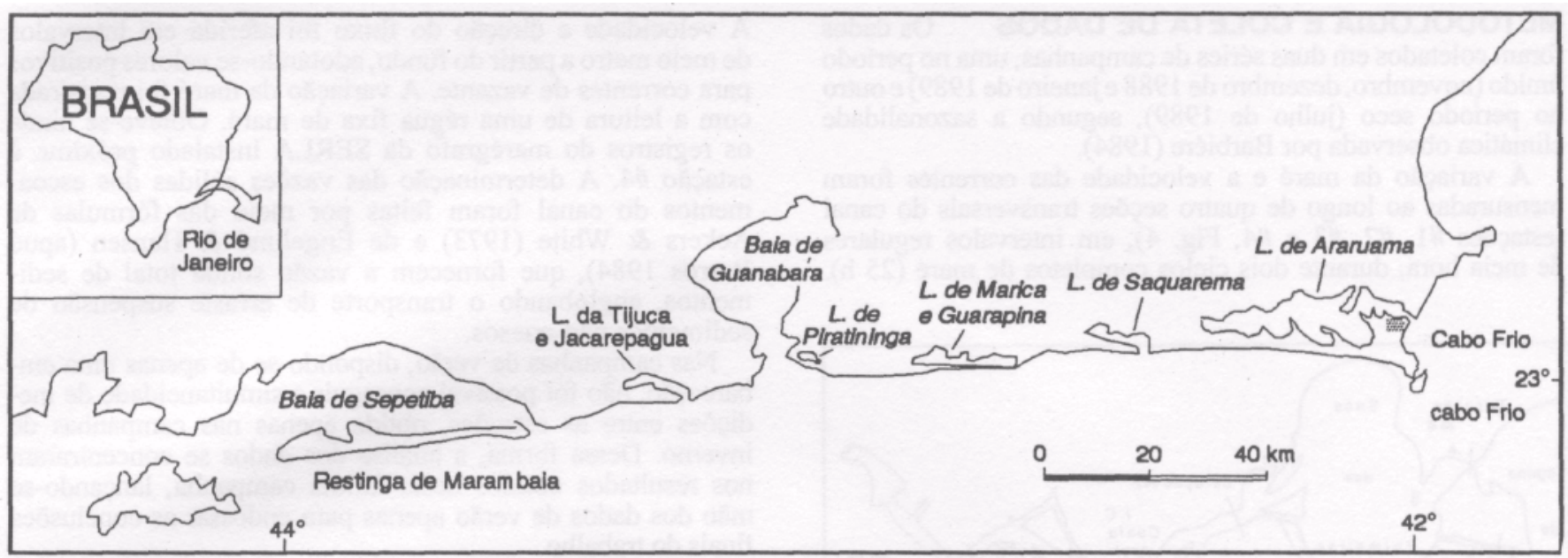

Figura 1 - Localização das lagunas entre a Baía de Sepetiba e o Cabo Frio Figure 1 - The coast lagoons between Sepetiba Bay and Cabo Frio

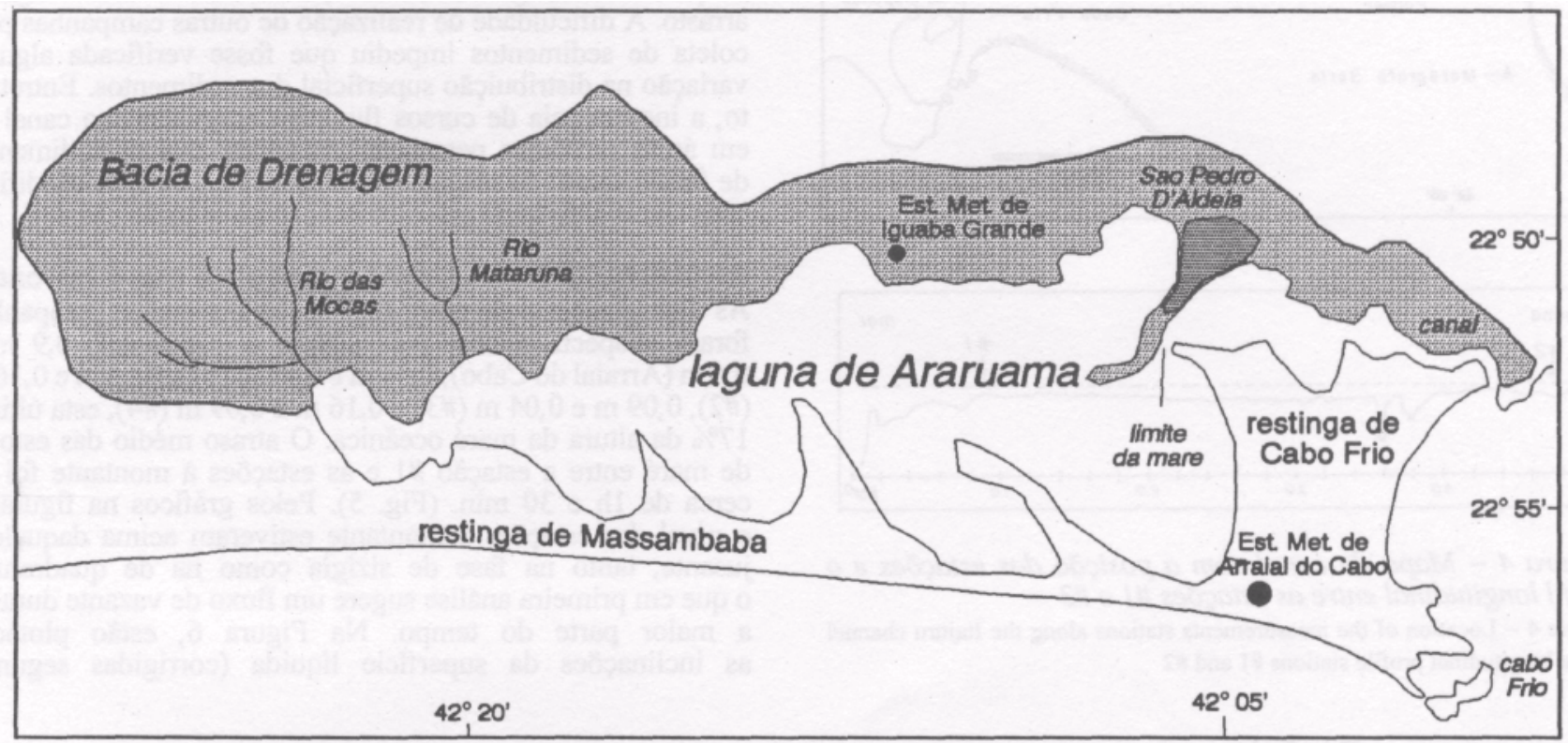

Figura 2 - Região da laguna de Araruama com a delimitação da bacia de drenagem, estações meteorológicas e limite da influência da maré oceânica (segundo Accetta 1987)

Figure 2 - The meteorological stations near Araruama lagoon, the limit of tidal incursion (Accetta 1987) and the limits of the catchment

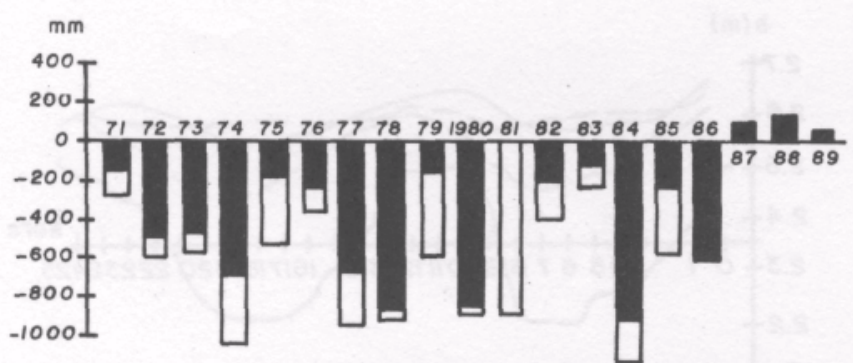

Figura 3 - Perfil do balanço precipitação-evaporação, para os últimos 20 anos, na localidade de Iguaba Grande (barra cheia), Arraial do Cabo (barra vazia), mostrando claramente o caráter semi-árido da região. Os valores para 1989 cobrem apenas os primeiros sete meses do ano

Figure 3 - The difference between precipitation and evaporation in the last 20 years at Iguaba Grande (full bar) and Arraial do Cabo (empty bar), well showing the semi-aridity of the region. Value for 1989 regards the period from January to July oscila em resposta aos eventos meteorológicos, sendo registradas, de acordo com marégrafos da Secretaria Estadual de Rios c Lagoas (SERLA), no interior da mesma, variações de até $0,25 \mathrm{~m}$ com a passagem de uma frente fria e aumento da pluviosidade.

O estado de hipersalinidade das águas da laguna, aliado à formação de deltas de enchente presentes no canal, à pequena contribuição de água doce típica de clima semi-árido e, conseqüentemente, à reduzida vazão sólida da laguna para o canal, permitem formular as seguintes hipóteses: 1. o gradiente provocado pela variação astronômica da maré é o principal elemento causador da circulação no canal; 2. ocorre a preponderância das correntes de enchente sobre as de vazante; e 3. a plataforma continental interna é a principal fonte de sedimentos para o assoreamento do canal.

O objetivo deste trabalho é verificar a validade das hipóteses apresentadas. Para tal fim, serão investigadas as variações, no tempo e espaço, da onda de maré, das correntes resultantes e o transporte de sedimentos associado, considerando a sazonalidade climática presente na região. 
Metodologia E COLETA DE DADOS Os dados foram coletados em duas séries de campanhas, uma no período úmido (novembro, dezembro de 1988 e janeiro de 1989) e outro no período seco (julho de 1989), segundo a sazonalidade climática observada por Barbiére (1984).

A variação da maré e a velocidade das correntes foram mensuradas ao longo de quatro seções transversais do canal (estações \#1, \#2, \#3 e \#4, Fig. 4), em intervalos regulares de meia hora, durante dois ciclos completos de maré $(25 \mathrm{~h})$.
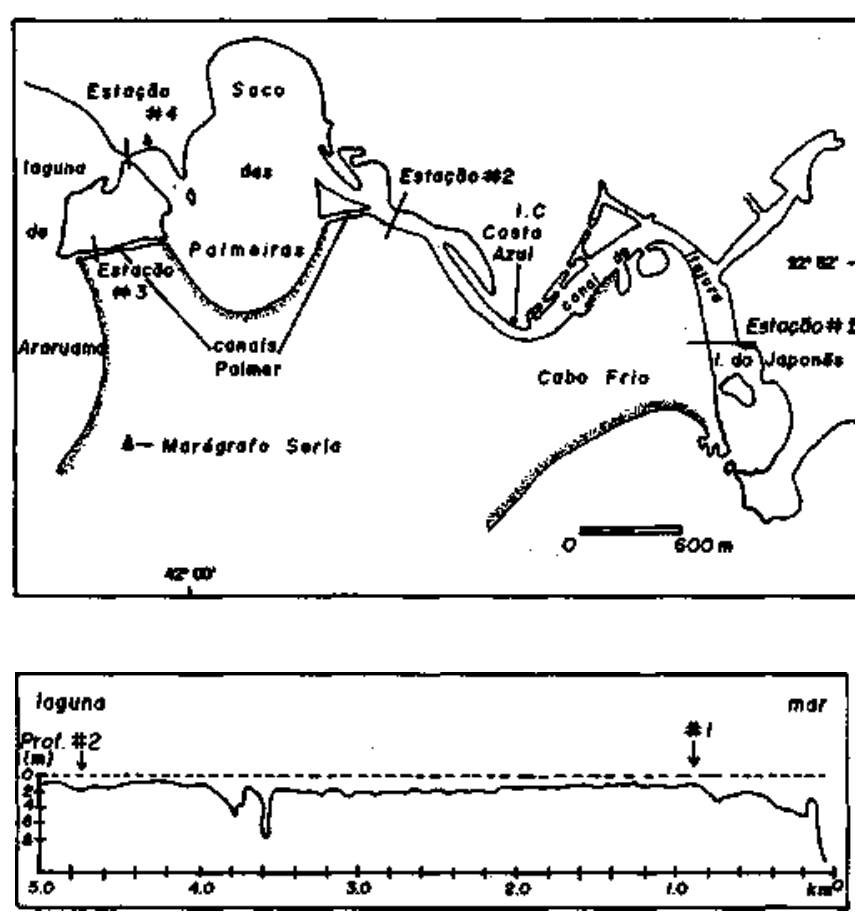

Figura 4-Mapa do canal com a posição das estações e o perfil longitudinal entre as estações \#1 e \#2

Figure 4- Location of the measurements stations along the Itajuru channel and a longitudinal profile stations \#1 and \#2
A velocidade e direção do fluxo foi aferida em intervalos de meio metro a partir do fundo, adotando-se valores positivos para correntes de vazante. A variação da maré foi registrada com a leitura de uma régua fixa de maré. Obteve-se ainda os registros do marégrafo da SERLA instalado próximo à estação \#4. A determinação das vazões sólidas dos escoamentos do canal foram feitas por meio das fórmulas de Ackers \& White (1973) e de Engelund \& Hansen (apud Barros 1984), que fornecem a vazão sólida total de sedimentos, englobando o transporte de arraste suspensão de sedimentos não-coesos.

Nas campanhas de verão, dispondo-se de apenas uma embarcação, não foi possível conseguir a simultaneidade de medições entre as estações, obtida apenas nas campanhas de inverno. Dessa forma, a análise dos dados se concentraram nos resultados obtidos nesta última campanha, lançando-se mão dos dados de verão apenas para endossar as conclusões finais do trabalho.

As coletas de sedimentos superficiais no fundo do canal foram feitas em apenas uma ocasião (verão de 1989), cobrindo 33 pontos ao longo de seu eixo, utilizando-se uma draga de arrasto. A dificuldade de realização de outras campanhas para coleta de sedimentos impediu que fosse verificada alguma variação na distribuição superficial dos sedimentos. Entretanto, a inexistência de cursos fluviais desaguando no canal ou em áreas próximas permitem considerar que os sedimentos de fundo sejam de origem marinha e que não haja modificações significativas de sua distribuição no leito do canal.

RESULTADOS A propagação da maré do canal As alturas médias de maré registradas durante as campanhas foram, respectivamente para sizígia e quadratura: $0,9 \mathrm{~m}$ e 0,4 m (Arraial do Cabo), 0,84 m e 0,29 m (\#1), 0,44 m e 0,16 m (\#2), 0,09 m e 0,04 m (\#3) e 0,16 m e 0,09 m (\#4), esta última $17 \%$ da altura da maré oceânica. $\mathrm{O}$ atraso médio das estofas de maré entre a estação \#1 e as estações à montante foi de cerca de 1 h e 30 min. (Fig. 5). Pelos gráficos na figura 5 , o nível das estações à montante estiveram acima daquele à jusante, tanto na fase de sizígia como na de quadratura, o que em primeira análise sugere um fluxo de vazante durante a maior parte do tempo. Na Figura 6 , estão plotadas as inclinações da superfície líquida (corrigidas segundo

\section{Sizigia}
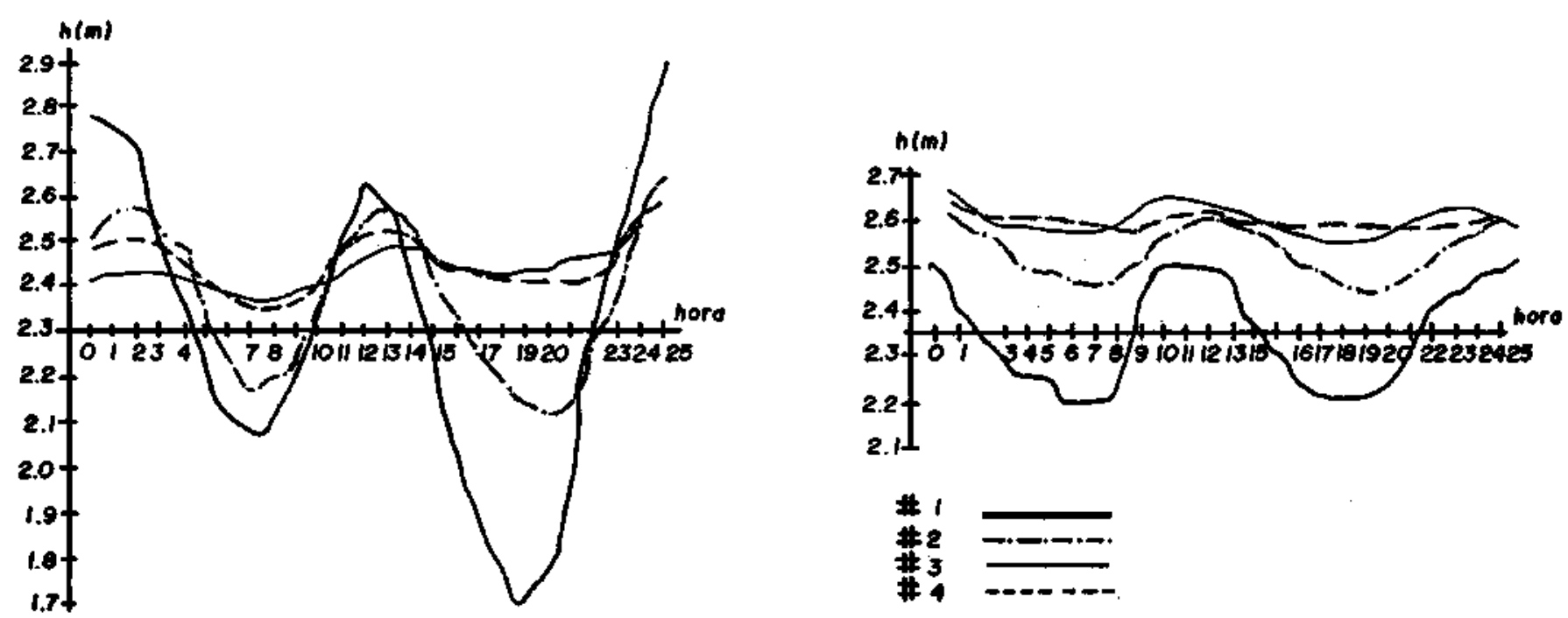

Figura 5- Gráficos da variação simultânea da maré nas quatro estações nos períodos de sizígia e quadratura. Nível médio referente à estação \#1

Figure 5 - Simultaneous tidal measurements at the four stations during and neap tide. Mean level refers to station \# 1 

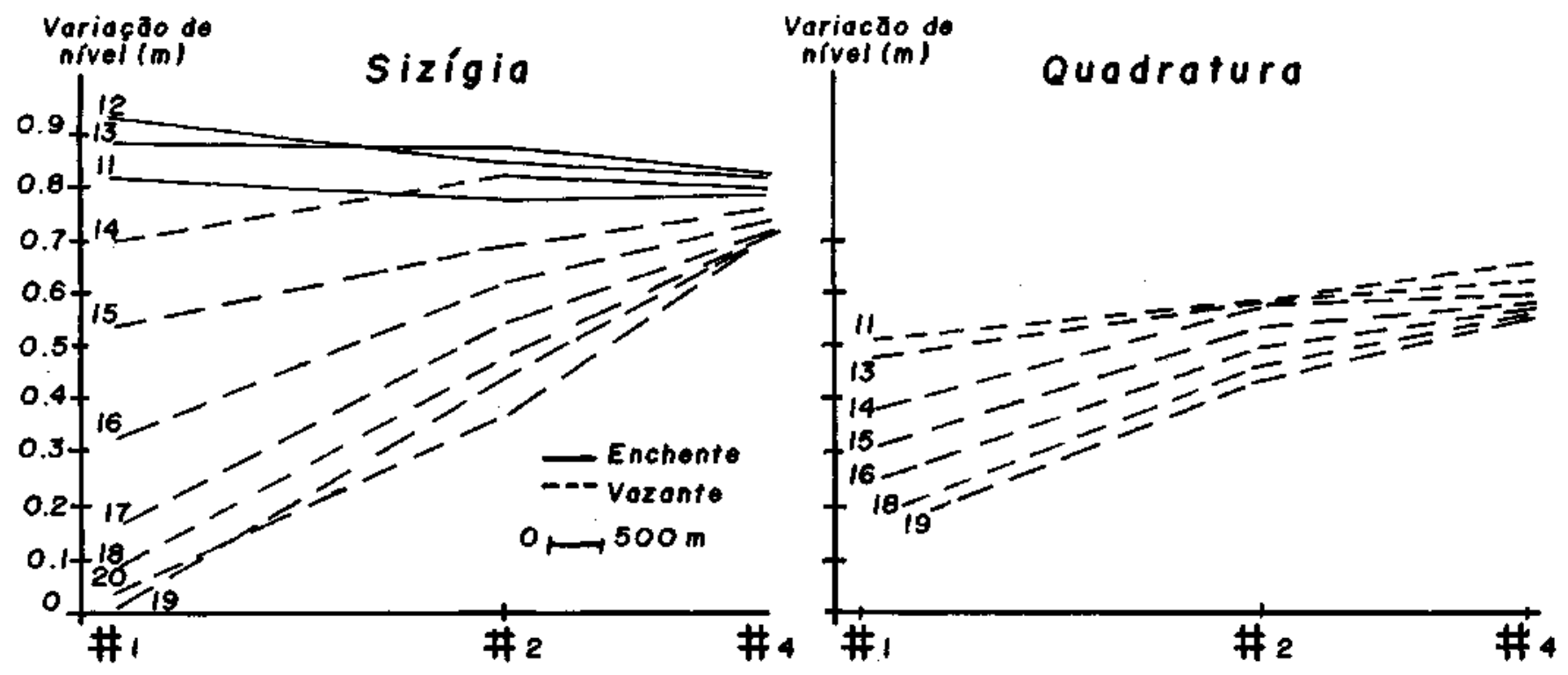

Figura 6 - Perfis instatâneos de declividade da linha d'agua para um determinado período de tempo em sizígia e quadratura. A numeração dos traços refere-se às horas após o inicio das medições

Figure 6 - Water surface gradient along the channel for a certain period of the time during spring and neap tide. The numbers refers to the time, in hours, after the beginning of the measurements

Knight 1981) para um determinado período em sizígia e quadratura. Observa-se que os gradientes na maré vazante foram maiores que na maré enchente.

A diferença observada entre o nível médio das estações decorre da sobrelevação do nível lagunar em resposta à maior taxa de precipitação no mês de junho $(147,2 \mathrm{~mm}$ segundo o Posto Meteorológico de Iguaba Grande, sendo que a média mensal do mês mais úmido registrada é de $115,7 \mathrm{~mm}$ ). A precipitação verificada no intervalo entre a campanha de sizígia e quadratura (33,7 $\mathrm{mm}$ em 7 dias) elevou o nível d'agua no canal em cerca de $0,15 \mathrm{~m}$.

Observa-se, nas estações interiores do canal, a assimetria negativa assumida pela onda de maré, onde, de acordo com o marégrafo da SERLA, o período de maré enchente é inferior ao de maré vazante, respectivamente $5 \mathrm{~h} 12 \mathrm{~min}$ e $7 \mathrm{~h} 12 \mathrm{~min}$ na estação \#4. A assimetria e o amortecimento da onda de mare verificados no interior do canal é resultado da distorção da maré astronômica ao se propagar por um sistema estuarino raso. Esta distorção é resultado do crescimento não-linear das constantes harmônicas da maré oceânica, principalmente M2 e M4, conseqüência dos efeitos de fricção ao longo do canal (Aubrey \& Speer 1985). A razão M4/M2 é um indicador primário, diretamente proporcional, da não-linearidade de crescimento das constantes harmônicas que, caso ocorra, promoverá o crescimento da amplitude de M4 para o interior do estuário, ou então seu decréscimo a uma taxa inferior à de M2.

Analisando a amplitude das constantes na boca da barra e no Costa Azul Iate Clube (3000 m adentro, Fig. 4), observa-se que a razão M4/M2 passa de 0,07 na boca dá barra para 0,12 no Costa Azul. Ocorre, nesse intervalo, uma redução de 50\% na amplitude de M2 e de apenas $16 \%$ na de M4, resultando na assimetria da maré. Em condições normais, sem qualquer anomalia meteorológica, esta assimetria assume um papel geológico importante, pois pode provocar um fluxo mais intenso, de menor duração e mais capacidade de transporte na maré enchente. O resultado deste processo é o assoreamento do estuário e a formação de deltas de enchente, o que é observado na presença de depósitos sedimentares dentro do canal.

O comportamento das correntes Para chegar a um valor de velocidade média representativo para toda a seção $(\bar{U})$ e não só para o taivegue, as velocidades médias no eixo principal das seções $(\bar{U})$ foram divididas por 1,16, valor encontrado por Knight (1981) para a razão entre velocidade média no talvegue e velocidade média na seção transversal. De acordo com as figuras 7 e 8 , não só os valores máximos de velocidade foram obtidos durante a vazante, mas também que o fluxo de vazante foi preponderante sobre o fluxo de enchente; durante todo o tempo. Em sizígia, o fluxo foi nega-tivo (enchente) em apenas $38 \%$ do tempo na estação \#1 e em $32 \%$ do tempo nas estações \#2, \#3 e \#4, sendo que, em quadratura, o fluxo foi de vazante durante todo p período de observação. Os valores de velocidade média indicaram uma grande oscilação, mais expressiva em quadratura, relacionada à penetração de ondas, geradas na plataforma, com períodos que variaram entre 2 e 12 horas (Lessa 1990a). Para suavizar as oscilações e evitar interferência de fenômenos externos, foram calculadas médias móveis para intervalos de quatro valores de velocidade média, as quais foram utilizadas no cálculo de transporte dos sedimentos. A tabela 1 fornece os valores das médias das velocidades médias filtradas de cada estação para períodos de enchente e vazante em sizígia e quadratura.

A velocidade do fluxo em um canal de maré é proporcional ao gradiente de pressão criado com a variação da maré, no lado oceânico, em relação ao nível lagunar. Durante as campanhas, o nível médio lagunar esteve mais alto que o nível médio do mar, gerando um gradiente de pressão direcionado para o oceano e a conseqüente predominância das correntes de vazante, pois estes gradientes só eram invertidos em instantes próximos à preamar. Devido à maior declividade da superficie líquida durante a baixamar, as correntes de vazante assumiram maiores valores.

Caracterização dos sedimentos de fundo Segundo a classificaçã̃o de Wentworth, encontram-se, de acordo com a média, quatro províncias granulométricas no canal (Fig. 9), variando de areia muito fina e areia grossa. Sua distribuição espacial intercala províncias de areia fina e média, o que parece ser resultado de dragagens realizadas em 1978 e 1980. No saco das Palmeiras, a distribuição textural, com sedimentos mais finos ao norte e mais grossos ao sul, parece estar de algum modo influenciada pelo regime de ventos da região. A predo- 

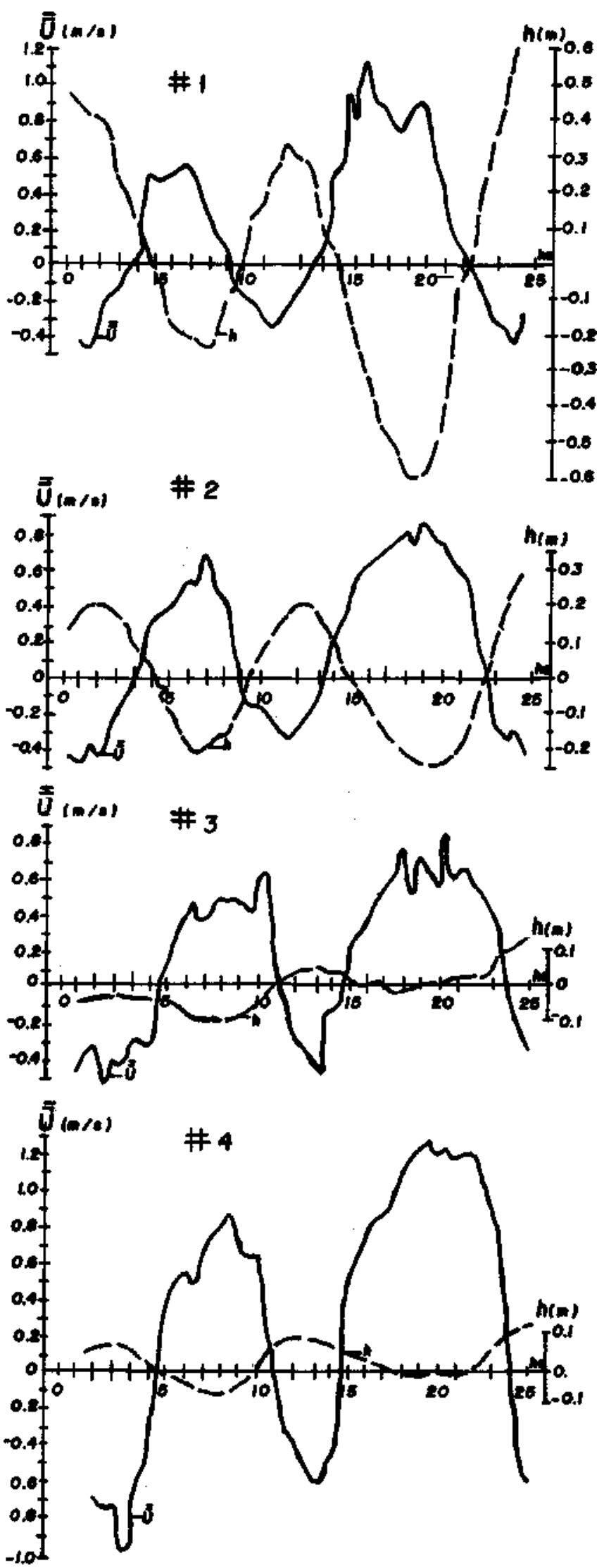

Figura 7- Gráficos da variação da velocidade média da corrente $U$, junto à variação da maré ( $h$ ), nas quatro estações, no período de sizígia

Figure 7 - Average current velocity $(\mathrm{U})$ and tide (h) variation during spring tide at the four stations
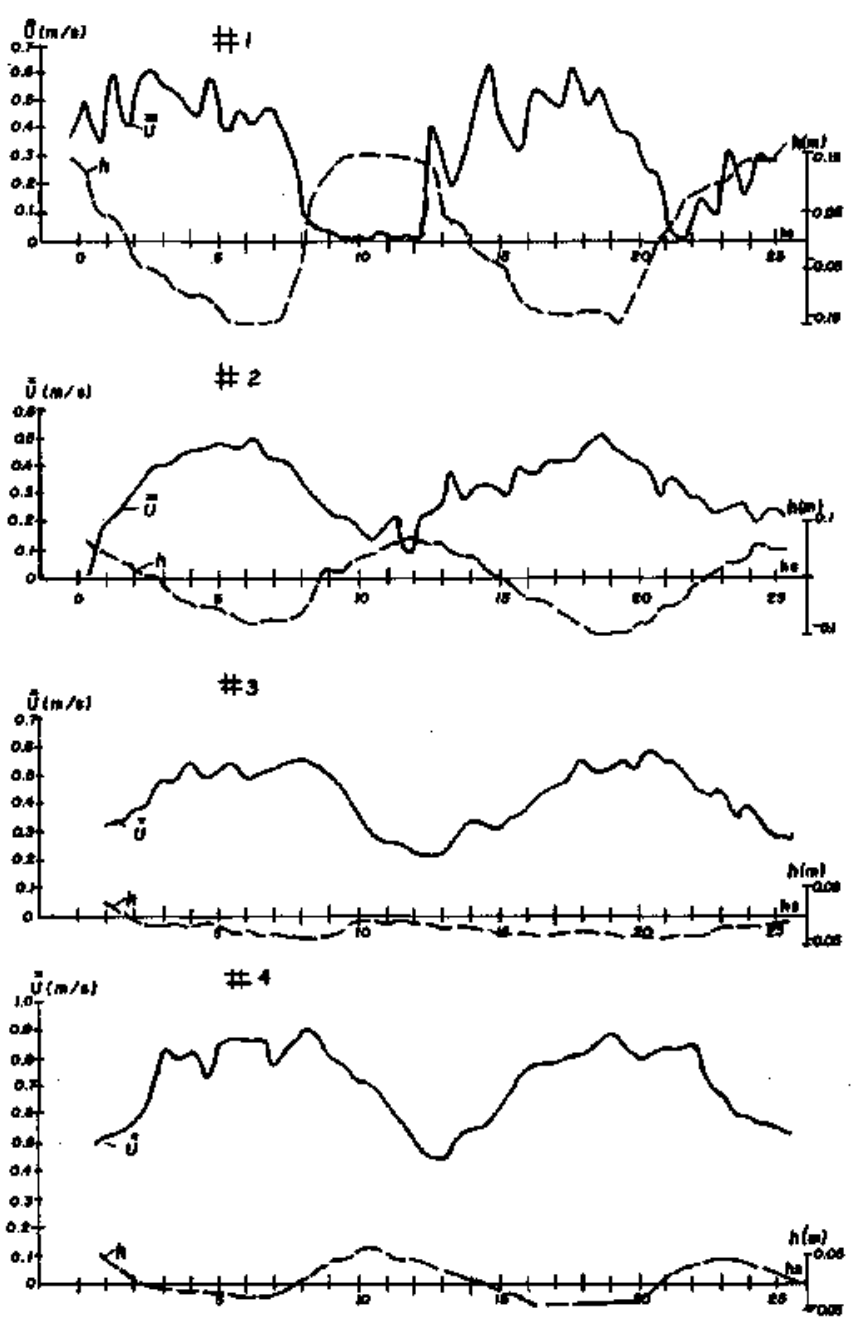

Figura 8 - Gráficos da variação da velocidade média da corrente $U$, junto à variação da maré (h), nas quatro estações, no período de quadratura

Figure 8 - Average current velocity (U) and tide (h) variant during neap tide at the four stations

Tabela 1 - Valores das velocidades médias de corrente (em $\mathrm{m} / \mathrm{s}$ ) para os fluxos de enchente e vazante

Table 1 - Average ebb and flood current velocites $(\mathrm{m} / \mathrm{s})$

\begin{tabular}{|c|c|c|c|c|}
\hline & \multicolumn{2}{|c|}{ SIZIGIA } & \multicolumn{2}{|c|}{ QUADRATURA } \\
\hline & Vazante & Enchente & Vazante & Enchente \\
\hline Estaçäo\#1 & 0,39 & $-0,18$ & 0,25 & $-0,19$ \\
\hline Estaçăo \#2 & 0,42 & $-0,29$ & 0,28 & $-0,25$ \\
\hline Estação\#3 & 0,44 & $-0,29$ & 0,32 & * \\
\hline Estaçāo\#4 & 0,63 & $-0,38$ & 0,62 & $\bullet$ \\
\hline
\end{tabular}

* Năo houve fluxo

minância do vento nordeste favorece a presença de um ambiente mais energético na porção sul e, provavelmente, forma correntes secundárias dirigindo-se para o norte devido à sobrelevação do nível da laguna nesta área, carreando o material mais fino e deixando o mais grosso.

As características texturais das amostras do material de fundo de cada uma das estações são apresentadas na tabela 2 . A velocidade crítica de cisalhamento $\left(\mathrm{u}_{\mathrm{c}}{ }^{*}\right)$ para cada uma das 
estações foi calculada utilizando-se o diagrama de Shields modificado por Yalin (Yalin 1977).

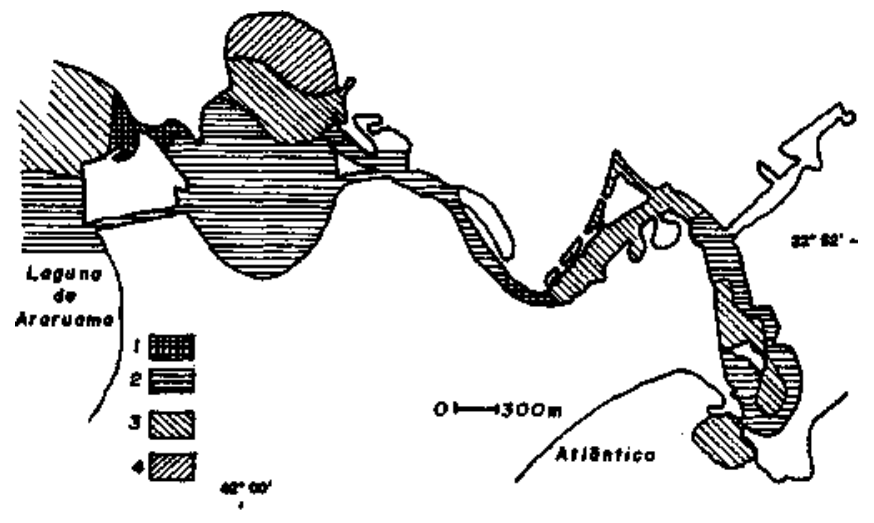

Figura 9-Distribuição superficial dos sedimentos defendo do canal de acordo com a média. 1. areia grossa $(0,50$ a $1,0 \mathrm{~mm}) ; 2$ areia média $(0,25$ a $0,50 \mathrm{~mm}) ; 3$. areia fina $(0,125$ a $0,25 \mathrm{~mm}) ; 4$. areia muita fina $(0,062$ a $0,25 \mathrm{~mm})$

Figure 9 - Mean grain size distribution of the surface sediments of the channel. 1. coarse sand $(0.50$ to $1.0 \mathrm{~mm}) ; 2$. medium sand $(0.25$ to $0.50 \mathrm{~mm}) ; 3$. fine sand $(0.125$ to $0.25 \mathrm{~mm})$; 4 . very fine sand $(0.062$ to $0.25 \mathrm{~mm})$

Tabela 2 - Características texturais dos sedimentos de fundo $e$ a velocidade de cisalhamento crítica $\left(u_{c^{*}}\right)$ nas quatro estações do canal

Table 2 - Textural characteristics of the sediments and the critical shear velocity $(\mathrm{u},$.$) at the four sections within the channel$

\begin{tabular}{l|l|l|l|l}
\hline Parámetro/Seçao & \multicolumn{1}{|c|}{$\# 1$} & $\# 2$ & $\# 3$ & $\# 4$ \\
\hline Média(mm) & 0,23 & 0,33 & 0,32 & 0,55 \\
Mediana (mm) & 0,20 & 0,31 & 0,29 & 0,62 \\
Moda (mm) & 0,177 & 0,25 & 0,25 & 0,35 \\
Desviopadrão(mm) & 0,12 & 0,11 & 0,13 & 0,41 \\
$\mathbf{u}_{v^{*}}(\mathrm{~m} / \mathrm{s})$ & 0,013 & 0,014 & 0,013 & 0,017 \\
\hline
\end{tabular}

Cálculo do transporte de sedimentos Investigando o transporte de sedimentos no estuário do Rio Potengi, Barros (1984) escolheu as fórmulas citadas como as que forneceram melhores resultados entre quatro fórmulas utilizadas. De acordo com Sleath (1984), o resultado das comparações de várias fórmulas, feitas pela American Society of Civil Engeneers, White et al. e Yang e Molinas, somando mais de 2.300 medições, indicaram as fórmulas de Ackers \& White (1973) e Engelund e Hansen como as de melhor resultado.

A fórmula de Ackers \& White (1973) fornece a taxa de sedimentos transportados, em $\mathrm{m}^{3} / \mathrm{s}$, sendo sua expressão:

$$
\begin{aligned}
& q s=L \bar{U} \quad h \quad \frac{1}{(1-p)} \frac{D}{h}\left(\frac{U}{u^{*}}\right)^{*} C \frac{\sqrt{F}-A^{m}}{A} \\
& \text { sendo, } R=D\left(\frac{Y_{1}}{e v^{2}}\right)^{1 / 3} \\
& n=1-0,2432 \ln (R) \\
& m=(9,66 / R)+1,64 \\
& A=(0,23 / R)+0,14
\end{aligned}
$$

$\ln (C)=2,86 \ln (R)-0,4343(\ln (R))^{2}-8,128$
$\mathrm{F}=\frac{\left(\mathrm{u}^{*}\right)^{2} e}{\mathrm{Y}, \mathrm{D}}\left|\frac{\mathrm{U}^{2}}{\left.\mid 2,5 \ln \left(\frac{1 \mathrm{l} h}{\mathrm{D}}\right)\right]^{2}}\right|^{(1 \omega)}$

$Y_{i}=$ peso específico do grăo no fluido $=[(e,-e) \mathrm{g}]$, sendo $e_{\varepsilon}$ a densidade do sedimento submerso $\left(2.650 \mathrm{~kg} / \mathrm{m}^{3}\right)$

$v=$ viscosidade cinemática da água $\left(10^{-6} \mathrm{~m} / \mathrm{s}^{2}\right)$

$\mathrm{D}=$ diámetro mediano do grtó (m)

$\overline{\mathrm{U}}=$ velocidade media da corrente $(\mathrm{m} / \mathrm{s})$

$\mathbf{L}=$ largura da secaáo transversal (m)

$\mathrm{u}^{*}=$ velocidade de cisalhamento $(\mathrm{m} / \mathrm{s})=(\mathrm{g} \mathrm{h} \mathrm{S})^{1 / 2}$

$h=$ altura da lâmina d'água (m)

$p=$ porosidade da areia $(0,46)$

$s=$ inclinaçso da superficie liquida, calculada segundo Knight.

Se R assumir valores menores que 1 , a equação deixará de ser recomendada, pois estes valores correspondem a sedimentos coesivos (Sleath 1984).

A equação de Engelund e Hansen, com resultados $\mathrm{em} \mathrm{m}^{3} / \mathrm{s}$, é

$\mathrm{qs}=0,05 \mathrm{~L} \mathrm{U}^{2} \sqrt{\frac{\mathrm{D} e}{\mathrm{Y}_{\mathrm{t}}} \mathrm{Y}^{32}}$

dada por:

onde, $\bar{U}=$ velocidade média da corrente $(\mathrm{m} / \mathrm{s})$

$\mathrm{L}=$ largura da seção transversal

$\mathrm{D}=$ diầmetro mediano do grão $(\mathrm{m})$

$\mathrm{Y}=$ número de mobilidade de Reynolds $=\frac{e \mathrm{u}^{* \mathbf{2}}}{\mathrm{Y}_{2} \mathrm{D}}$

A equação 9 não é recomendada para casos em que 0 diâmetro mediano for inferior a $0,15 \mathrm{~mm}$ e/ou desvio padrão maior que $2 \mathrm{~mm}$, como também para casos em que a tensão cisalhante do fundo for inferior a $\mathrm{kgfm}^{2}\left(\mathrm{u}^{*}<0,012 \mathrm{~m} / \mathrm{s}\right)$ (Brunn 1978). Nos momentos de inversão de fluxo nos canais de maré, ps valores da tensão cisalhante podem ser menores que os mencionados. Além disso, esta fórmula não considera o movimento incipiente do grão, podendo assim superdimensionar os valores de vazão sólida.

Os resultados das vazões sólidas das duas fórmulas para cada estação, ao longo dos dois ciclos de maré em fase de sizígía e quadratura, estão plotados nas figuras 10 e 11, junto ao gráfico da maré (valores normalizados). Observa-se, pelos gráficos, que os maiores valores de vazão sólida são encontrados nos períodos de vazante, num comportamento similar àquele adotado pelas velocidades médias.

Os resultados das duas fórmulas apresentaram o mesmo comportamento ao longo do tempo, sendo que os valores segundo a equação 9 se mostraram superiores em relação aos da equação 1 . A diferença apresentou tendência a diminuir; quando as vazões atingiram valores superiores a $10^{-3} \mathrm{~m}^{3} / \mathrm{s}$, em situações de elevadas velocidades e tensões cisalhantes. Nos momentos próximos às inversões de fluxo, quando os valores de velocidade média e cisalhante estavam reduzidos, a equação 1 indicou transporte nulo, pois considera o movimento incipiente do grão. Foi observado, entretanto, que os valores críticos de $\mathrm{u}^{*}$ foram mais elevados do que aqueles encontrados pelo gráfico de Shields.

Os valores totais de transporte, mostrados na figura 12 , indicam o volume total de sedimentos que transitou pelas quatro estações, em sizígia e quadratura, durante os dois ciclos de maré. Em sizígia, quando houve inversão de fluxo, o volume de sedimentos transportados na vazante foi bastante superior ao de enchente, sendo a estação \#4 a única a indicar valores negativos de transporte segundo a equação 1 . As diferenças existentes entre os resultados das duas fórmulas fica aqui melhor evidenciado, com valores totais da equação 9 chegando a superar em 15 vezes os da equação $l$. 
Vazão tólldd $(\bar{m} / 9)$

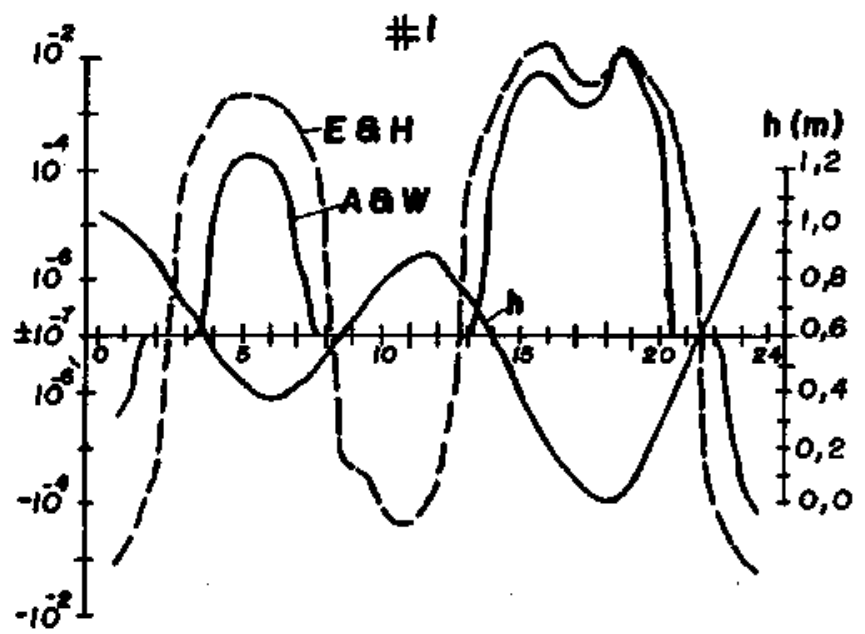

Vazão

\section{sólida $(m / s)$}

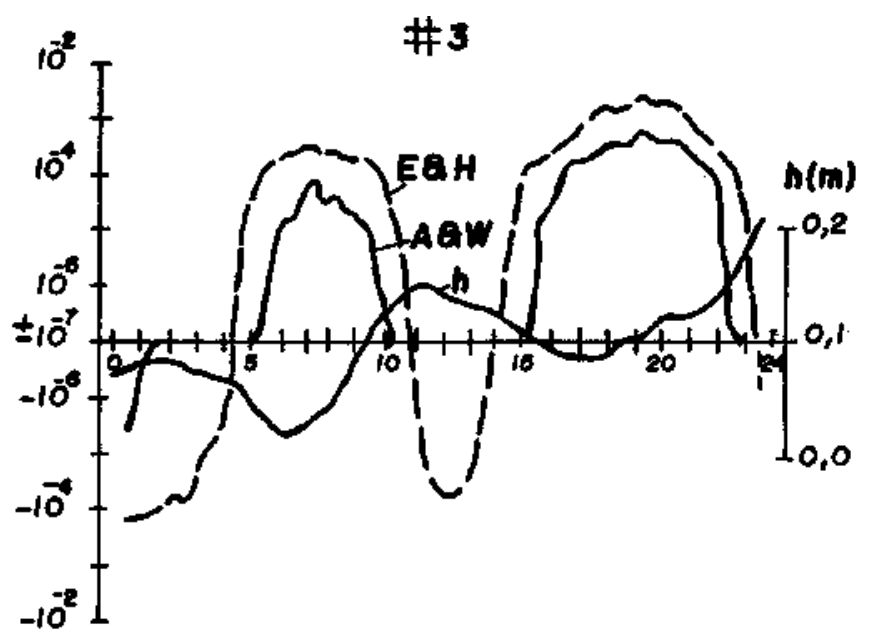

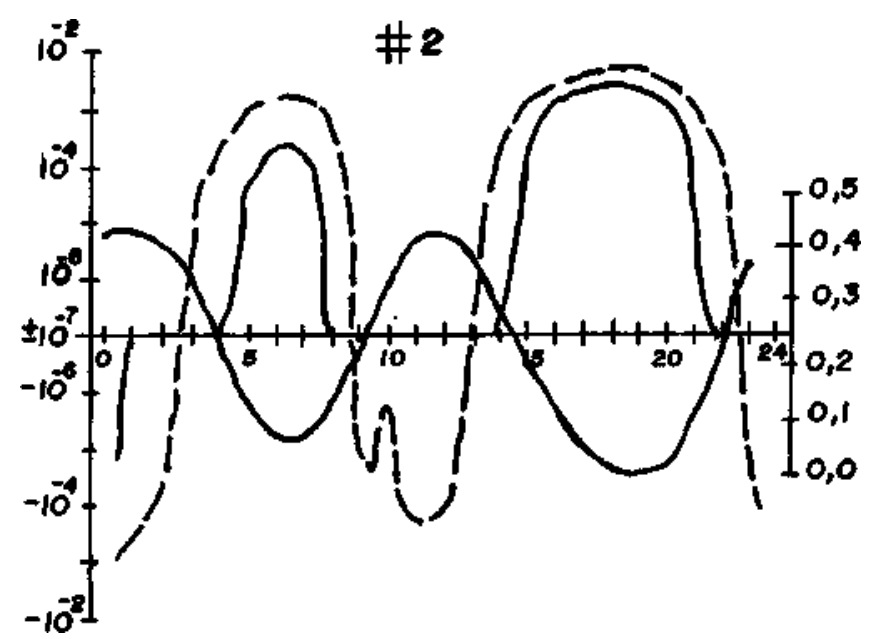

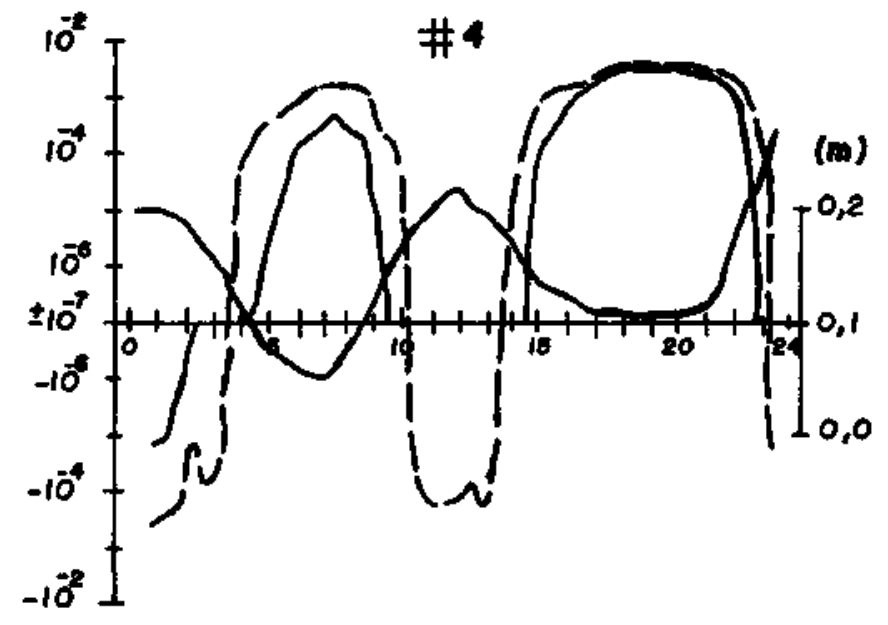

Figura 10 - Gráficos de variação do volume de sedimentos transportados nas quatro estações segundo as equações 1 e 9, junto as curvas de variação da maré no período de sizígia

Figure 10 - Fluctuations on the volume of sediments transported at the four stations of the channel, in accordance with equations 1 and 9 , and the tidal variation in the spring tide

Analisando os totais médios de cada estação, observa-se que a maior capacidade de transporte foi encontrada na estação \#1, seguida pelas estações \#3 e \#4 somadas (isto porque posicionam-se de modo similar em relação ao saco das Palmeiras e laguna) e, por fim, a estação \#2 com menor capacidade de transporte. Dos valores residuais entre as estações, verifica-se a tendência de assoreamento no saco das Palmeiras $\left(113 \mathrm{~m}^{3}\right.$ em sizígia e $50,7 \mathrm{~m}^{3}$ em quadratura) e a tendência à erosão no trecho que se extende entre as estações \#2 e \#1 $\left(-54,7 \mathrm{~m}^{3}\right.$ em sizígia e $-53,1 \mathrm{~m}^{3}$ em quadratura). No que diz respeito ao saco das Palmeiras, a possibilidade de assoreamento realmente ocorre, pois as características morfológicas desse trecho do canal, com aumento repentino das seções transversais, possibilita a redução das velocidades e a conseqüente deposição dos sedimentos. Já, no trecho entre as estações \#1 e \#2, deve-se ter cuidado ao adotar a tendência de erosão como verdadeira para todo o segmento, uma vez que é grande a distância entre as estações $(3.600 \mathrm{~m})$ e bastante variada a batímetria (Fig. 4).

CONCLUSÃO As observações feitas anteriormente à realização das campanhas previam o predomínio das correntes de enchente sobre as de vazante, e um maior volume de sedimentos transportados em direção à laguna, o que de fato não ocorreu. Além disso, foi verificado que o direcionamento das correntes foi mais influenciado pelo nível lagunar que pela variação da maré oceânica, invalidando, a priori, as hipóteses formuladas na introdução. Entretanto, as razões para tal resultado são explicadas pelas alterações da meteorologia regional, nos anos de 1987,1988 e 1989, quando ocorreu uma fase de maior umidade climática (Fig. 3), elevando o nível lagunar e provocando o predomínio das correntes de vazante. Os resultados das campanhas de verão (Lessa 1989) indicaram um comportamento similar aos obtidos no inverno, quando se esperava algo diferente por ser um período de seca na região. Este mesmo padrão deve ter se repetido desde 1987, como atestam os valores de salinidade média decrescentes da laguna (Lessa 1990b) e o aumento do nível lagunar, de acordo com os marégrafos da SERLA (Fig. 13).

Dessa forma, o comportamento diagnosticado não pode ser entendido como normal. O retorno às condições de semi-aridez provavelmente inverterão o quadro observado, o que possibilitaria explicar a existência de deltas internos no canal. Além disso, é necessário lembrar que o mesmo 

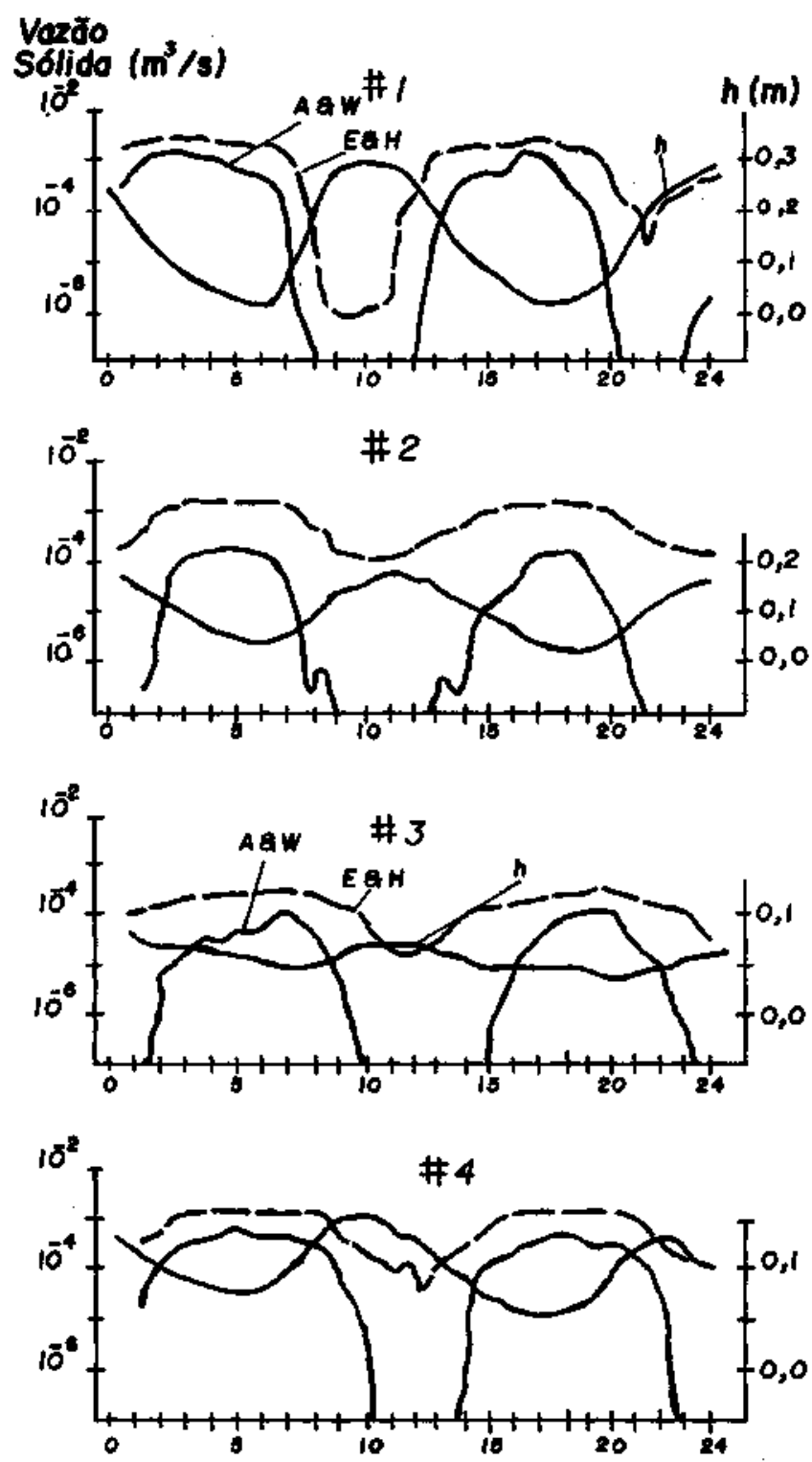

Figura 11 -Gráficos de variação do volume de sedimentos transportados nas quatro estações, segundo as equações 1 e 9, junto às curvas de variação da maré no período de quadratura

Figure 11 - Fluctuations on the volume of sediments transported at the four stations of the channel, in accordance with Equations 1 and 9, and the tidal variation in the neap tide

caráter assimétrico da onda de maré não produziu o resultado esperado, reforçando assim a idéia de anormalidade da situação atual.

A formação dos deltas e a pequena profundidade encontrada em trechos do canal têm provocado problemas à navegação e para o meio-ambiente. O tráfego de barcos com calado maior que dois metros só é possível em períodos de sizígia, o que age como um fator restritivo à indústria náutica local. No tocante ao aspecto ambiental, quanto mais raso o canal, menor a capacidade de penetração da onda de maré e a possibilidade de migração, para a laguna, de organismos marinhos que a utilizam como local de maturação (Pimenta et al. 1989). Assim sendo, a realização de uma dragagem, visando aprofundar os trechos mais assoreados, seria uma medida aconselhável. Resta, contudo, saber qiial o volume de material a ser dragado, pois a amplitude de maré no interior do canal

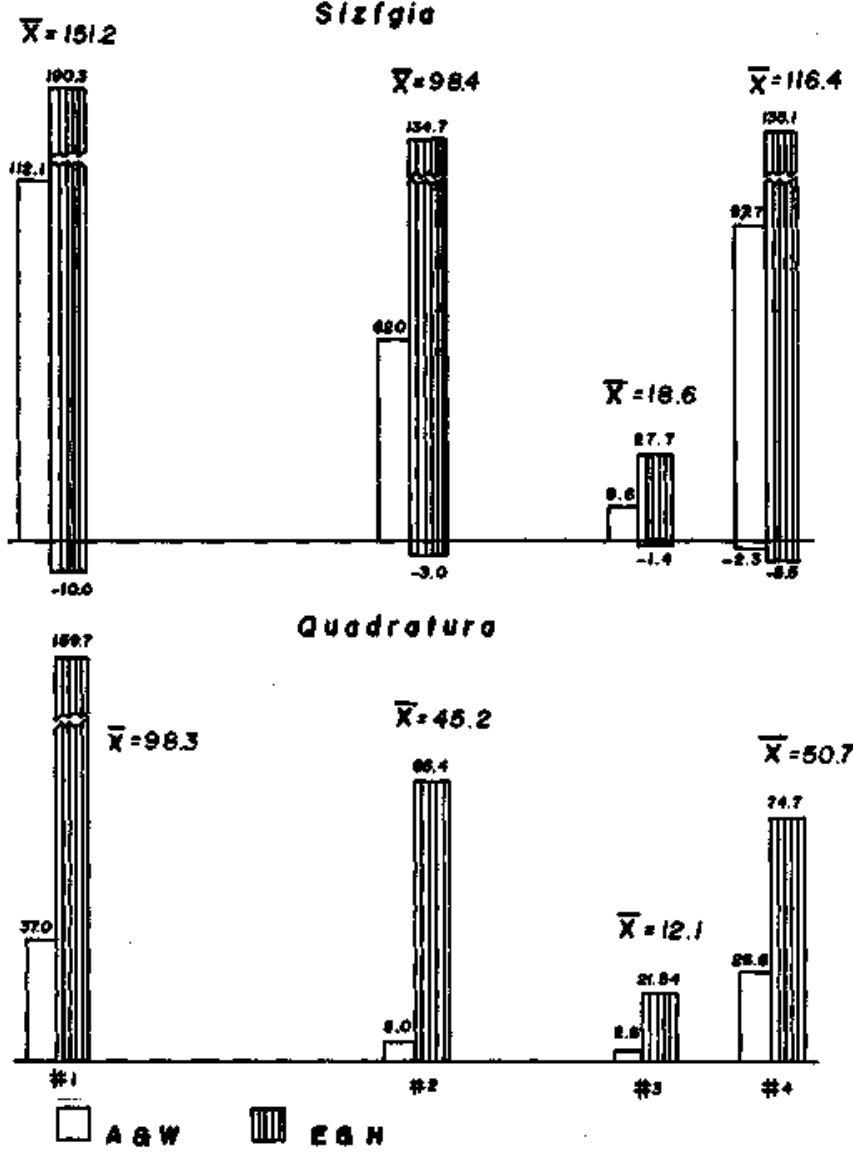

Figura 12 - Volume total de sedimentos transportados (em $\mathrm{m}^{3}$ ) nas quatro estações, em sizígia e quadratura, segundo as equações 1 e 9

Figure 12 - Total volume of sediments transported at the four stations during spring and neap tide, in accordance with Equations 1 and 9

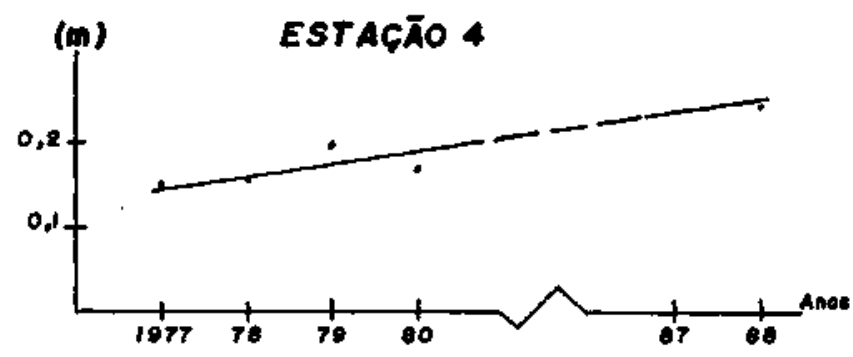

PRAIA DO hOSPfCIO - aRARUAMA

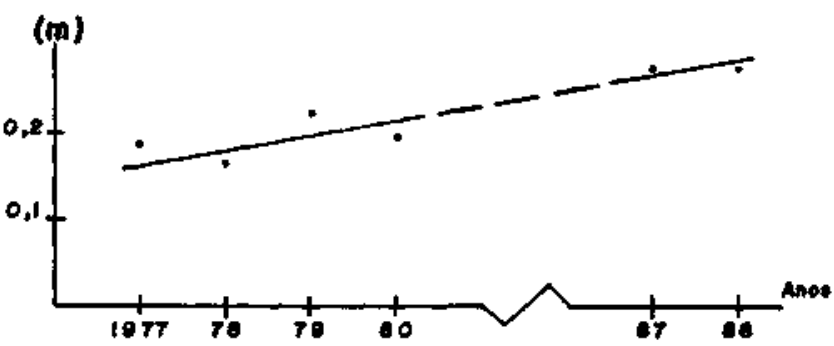

Figura 13 - Gráficos de variação do nível da laguna, segundo a média anual, em duas localidades: na cidade de Araruama (extremidade leste) e na estação \#4 (extremidade oeste) Figure 13 - Mean annual lagoon level variation at Araruama city (westernmost side of the lagoon) and near station \#4 (easternmost side of the lagoon) 
poderá ser aumentada devido à redução dó atrito na sua propagação, correndo-se o risco de inundações na área marginal do canal durante as preamares de sizígia (Lessa 1990a).

Foi observada a semelhança existente entre o canal de Itajuru e o Rio Potengi (Barros 1984), pois ambos parecem ter na variação da maré astronômica o principal agente de circulação estuarina, o que se deve à localização de ambos em regiões de pouca precipitação. Tendem a mostrar, no entanto, diferentes interações entre a geometria do canal e o deslo- camento da onda de maré, visto que, no primeiro, a maré adquire assimetria positiva (com correntes de enchente mais fortes) e, no segundo, assimetria negativa (com correntes de vazante mais fortes).

Agradecimentos Gostaria de externar meus agradecimentos ao dr. Dieter Muehe pela revisão crítica do texto. Este trabalho foi desenvolvido com auxílio da bolsa de mestrado do CNPq.

\section{REFERÊNCIAS BIBLIOGRÁFICAS}

ACCETTA, D. 1987. / Campanha de Medições Hidráulico-Sedimenlológicas na Lagoa de Araruama; Campanha de Verão. Rio de Janeiro, PORTOBRÁS. 126 p. (Boi. Técn., INPH-113/87).

ACKERS, P. \& WHITE, W.R. 1973. Sedimen transport: new approach and analysis. J. Hydraulics Division, 99(HY11):2941-2060.

AUBREY, D.G. \& SPEER, P.E. 1985. A study of non-linear tidal propagation in shallow inlet/estuarine systems. Part I: Observations. Estuarine, Coastral and Shelf Science, 21:185-295.

AYUP, R.N. 1986. O comportamento dos sedimentos em suspensão no rio De la Plata exterior e proximidades. Pesquisas, 18:36-68

AMADOR, E.S. 1980. Traços gerais da evolução quaternária da bacia do Rio São João. In: CONG. BRAS. GEOL., 31. Camboriú, 1980. Anais... Camboriú, S.B.G. v. 1, p. 542-555.

BARBIÉRE, E. 1984. Cabo Frio e Iguaba Grande: dois microclimas distintos em um curto intervalo espacial. In: RESTINGA: ORIGEM, ESTRUTURA E PROCESSOS. Niterói, 1984. Anais... Niterói, CEUFF. p. 5-13.

BARROS, A.N.S.S. 1984. A Capacidade de Transporte nos Escoamentos de Maré no Estuário do Rio Potengi. Rio de Janeiro. 242 p. (Dissertação de Mestrado, COPPE/UFRJ)

BRUUN, P. 1978. Stability of Tidal Inlets. New York, Elsevier. 507 p.

DOBEREINER, C.E. 1983. Importância do comportamento de suspensões no assoreamento de portos e estuários. Rev. Bras. Eng., 4:61-74.

DOBEREINER, C.E. 1986. Sedimentação no estuário do rio Itajaí-Açu. In: CONG. LATINOAM. DE HIDRÁULICA, 12. São Paulo, 1986. Anais... São Paulo. p. 1-12.

FONSECA, A.R.; HEILBRON, M.; CHRISPIN, S. 1987. Geologia estrutural de Cabo Frio e cabo de Búzio. In: SIMP. GEOL. REG. RJ/ES, 1. Rio de Janeiro, 1987. Anais... Rio de Janeiro, SBG. p. 385-416.

KNIGHT, p.W. 1981. Some field measurements concerned with the behaviour of resistance coefficients in a tidal channel. Estuarine, Coastal and Shelf Science. 12:303-322.

LESSA, G.C. 1989. Consideracões sobre o comportamento hidráulico do canal ile Itajuru - laguna de Araruama. In: SIMP. NAC. GEOG. FIS.
APLICADA, 3. Nova Friburgo, 1989. Anais... Nova Friburgo, UFRJ. p. 244-256.

LESSA, G.C. 1990a. Hidráulica e Sedimentação do Canal de Itajuru - Laguna de Araruama (RJ). Rio de Janeiro. 120 p. (Dissertação de Mestrado, UFRJ).

LESSA, G.C. 1990b. Anomalias climáticas e seus reflexos no comportamento hidráulico de maré da laguna de Araruama - RJ. In: SIMP. DE ECOSSISTEMAS DA COSTA SUL E SUDESTE BRASILEIRA, 2. Águas de Lindóia, 1990. Anais... Águas de Lindóia, Acad. Ciênc. São Paulo. v. 2, p. 63-72

MORAIS, J.O.; MEIRELES, A.J.; FREIRE, C.F.E. 1988. Processos hidrodinâmicos e material $\mathrm{cm}$ suspensão no estuário do Rio Pacoti, Ceará - Brasil. In: CONG. BRAS. GEOL., 35. Belém, 1988. Anais... Belém, SBG, v. 2, p. 581-591.

PIMENTA, E.G.; ROSA, A.S.; LOPES, M.F. 1989. Aspectos Gerais do Ecossistema de Cabo Frio. Cabo Frio, Una Cultural. (Rei. Técn.). (Inédito).

PONCANO, W. \& GIMENEZ A.F 1987 Reconhecimento sedimentológico do estuário do Itajaí-Açu. Rev. Bras. Geoc. 17(1):33-41.

POND, S \& PICKARD, G 1983. Introductory Dynamical Oceanography. New York, Pergamon Press. 329 p.

PRITCHARD, DW. 1952. Estaurine hydrography. In LANDSBERG, H.E. ed. Advances in Geophysics. New York, Academic Press. v. 1, p. 243-280

SLEATH, J.F. 1984. Sea Bed Mechanics. Cambridge, Wiley \& Sons.500p. YALIN, M.S. 1977. Mechanics of Sedment Transport. $2^{a}$ ed. Oxford, Pergamon Press. 320 p. 